\title{
Psychometric properties of the single-item measure, severity of worst tiredness, in patients with moderately to severely active rheumatoid arthritis
}

Elizabeth D. Bacci ${ }^{* *}$, Amy M. DeLozier², Chen-Yen Lin², Carol L. Gaich², Xiang Zhang ${ }^{2}$, Terence Rooney², Stephanie de Bono ${ }^{2}$, Richard Hoffman ${ }^{2}$ and Kathleen W. Wyrwich ${ }^{3}$

\begin{abstract}
Background: To assess the reliability, validity, and responsiveness to treatment change of the single-item measure, Severity of Worst Tiredness, in patients with rheumatoid arthritis (RA).

Methods: Data from two Phase 3, randomized, placebo-controlled (RA-BUILD; and active-controlled [RA-BEAM]), clinical studies of the efficacy of baricitinib in adults with moderately to severely active RA were used. The psychometric properties of the single-item measure, Severity of Worst Tiredness, were assessed, including test-retest reliability, convergent and discriminant validity, known-groups validity, and responsiveness, using other patient- and clinicianreported outcomes frequently assessed in RA patients.

Results: Test-retest reliability of the Severity of Worst Tiredness was supported through large intraclass correlation coefficients $(0.89 \leq \mathrm{ICC} \leq 0.91)$. Moderate-to-large correlations were observed between this patient-reported outcome (PRO) and other related patient- and clinician-reported assessments of RA symptoms and patient functioning, supporting construct validity of the measure ( $|r| \geq 0.41$ ). The instrument also displayed known-groups validity through statistically significant differences between mean values of the Severity of Worst Tiredness defined using other indicators of RA severity. Finally, responsiveness was supported by large and statistically significant differences in change scores from Day 1 to Week 12 for patients comparing responders and nonresponders using the American College of Rheumatology 20 (ACR20) criteria.
\end{abstract}

Conclusion: The Severity of Worst Tiredness PRO demonstrated adequate reliability, validity, and responsiveness in clinical trials of adults with moderately to severely active RA and is fit for purpose in this patient population.

Keywords: Rheumatoid arthritis, Tiredness, Fatigue, Patient-reported outcome, Psychometric, Reliability, Validity, Responsiveness

\section{Background}

Development of a standardized approach to assess key elements of disease activity in rheumatoid arthritis (RA) clinical trials has been the goal of Outcome Measures in Rheumatology Clinical Trials (OMERACT), American College of Rheumatology (ACR), and European League Against Rheumatism (EULAR) groups [1-3]. The core sets of measures developed by these groups include assessments and

\footnotetext{
* Correspondence: elizabeth.bacci@evidera.com

${ }^{1}$ Evidera, Inc., 1417 4th Avenue, Suite 510, Seattle, WA 98101, USA Full list of author information is available at the end of the article
}

composite indices that incorporate use of patient-reported outcomes (PROs) (e.g., daily functioning, change in disease activity), as well as clinical measures (e.g., erythrocyte sedimentation rate [ESR]) and clinician's assessments (e.g., clinician assessment of disease activity), to quantify disease activity and change over time [2]. However, patientcentered research has indicated that key outcomes important to patients were not originally captured by the core sets, such as fatigue, sleep, and general wellness [4], morning stiffness [5], and the patient's experience of social and psychological challenges and ability to cope [6]. 
Of these, fatigue is noted as one of the most common symptoms experienced by patients with RA [7]. Fatigue is a frequent and debilitating problem for patients with RA [8] and is second only to pain as the most bothersome patient-reported RA symptom [9]. The burden of fatigue in RA patients is well known, with symptom prevalence estimates ranging from $42 \%$ to $90 \%$ of patients with RA [7, 10, 11]. There is consistent agreement on the clinical relevance of fatigue and the impact fatigue has on activities of daily living and overall healthrelated quality of life (HRQOL) in RA [12, 13]. Indeed, both the 2007 Patient Perspective Workshop at OMERACT and the 2008 ACR/EULAR Task Force recommended that all RA clinical trials should update the core set of recommended measures of disease activity and report on fatigue [14, 15], although no specific instruments are endorsed.

Although fatigue in RA is a multidimensional concept [16-18], tiredness is a key component of fatigue. Arthritis Research UK [19] defines fatigue as "a feeling of extreme physical or mental tiredness," and the 13-item Functional Assessment of Chronic Illness TherapyFatigue (FACIT-F) Scale-a widely used measure of fatigue across many diseases, including RA-has six items that address this key component with "tired" in their wordings (e.g., "I feel tired," "I have trouble starting things because I am tired," "I have trouble finishing things because I am tired"). There is wide variation in how patients use the word fatigue when describing their symptom experience, with terms like "physical and mental tiredness" commonly associated with fatigue [20].

Moreover, qualitative interviews with RA patients that focused on the development of a new PRO demonstrated that "tiredness" is a more commonly used term to describe this symptom experience than "fatigue" [21]. Specifically, these one-on-one interviews were designed to explore and better understand the terminology RA patients most often use to report this burdensome symptom. In these interviews, the majority of participants $(n=20,71 \%)$ used "tiredness" to describe their RA symptom experiences, whereas fewer $(n=13,46 \%)$ mentioned "fatigue" [21].

Despite the recommendations for the need to assess this chronic aspect of RA, there is currently no commonly used and well-validated instrument to assess the patient's experience of this symptom in RA clinical trials [11]. To address this need, a daily electronic PRO diary single-item measure was created to assess the severity of worst tiredness from the patient's perspective. To develop this single-item measure, referred to as Severity of Worst Tiredness, a targeted literature review and interviews with healthcare providers were conducted in order to ascertain the appropriate terminology to be used for the measure. In addition, qualitative concept elicitation and cognitive debriefing interviews with RA patients were conducted, to ensure that the content of the scale was being accurately captured by the instrument, as well as to confirm that the measure is relevant, easy to use, and easy to understand by patients with RA [21]. This supported the content validity of Severity of Worst Tiredness by confirming the relevance of tiredness as an RA symptom and the appropriateness of the term "tiredness" to describe this symptom. However, although the content validity of Severity of Worst Tiredness was demonstrated, the psychometric properties of the measure have not yet been assessed.

The purpose of the present study is to assess the psychometric properties (i.e., reliability, validity, and responsiveness) of the Severity of Worst Tiredness PRO in patients with moderately to severely active RA who participated in two Phase 3 clinical trials, RA-BEAM and RA-BUILD, for baricitinib.

\section{Methods \\ Patient population \\ RA-BEAM}

RA-BEAM $(N=1305)$ was a randomized, double-blind, double-dummy, placebo- and active-controlled, parallelarm, 52-week study in patients aged $\geq 18$ years with active RA ( $\geq 6 / 68$ tender and $\geq 6 / 66$ swollen joints; serum high-sensitivity $\mathrm{C}$-reactive protein $[\mathrm{hsCRP}] \geq 6 \mathrm{mg} / \mathrm{L}$ ) with an inadequate response to methotrexate (MTX). The study was designed to assess improvements in disease activity, structural preservation, and PROs, including physical function, safety, and tolerability with oral baricitinib $4 \mathrm{mg}$ once daily. Full details regarding the conduct of the study, as well as the primary efficacy and safety outcomes of this study have been reported previously [22].

\section{RA-BUILD}

RA-BUILD $(N=684)$ was a randomized, double-blind, placebo-controlled, parallel-group 24-week study in patients aged $\geq 18$ years with active RA $(\geq 6 / 68$ tender and $\geq 6 / 66$ swollen joints; hsCRP $\geq 3.6 \mathrm{mg} / \mathrm{L}$ [upper limit of normal $3.0 \mathrm{mg} / \mathrm{L}]$ ) and an insufficient response (despite prior therapy) or intolerance to $\geq 1$ csDMARDs. The study was designed to assess improvements in disease activity, structural preservation, and PROs, including physical function, safety, and tolerability with oral baricitinib 2 and $4 \mathrm{mg}$ once daily. Full details regarding the conduct of the study, as well as the primary efficacy and safety outcomes of this study have been reported previously [23].

For both studies, the current analysis is on data between Weeks 0 to 12, utilizing other PRO and clinicianreported indicators of RA symptoms and severity assessed in the primary efficacy studies of RA-BEAM 
and RA-BUILD. Both studies were conducted with informed consent, under institutional review board approval, and in accordance with the Declaration of Helsinki (ClinicalTrials.gov number NCT01710358 [RABUILD] and NCT01721057 [RA-BEAM]).

\section{Instruments used in the psychometric analyses}

Patient-reported outcomes (PROs)

Severity of Worst Tiredness, Severity of Morning Joint Stiffness, Severity of Worst Joint Pain, and Duration of Morning Joint Stiffness Severity of Worst Tiredness, Severity of Morning Joint Stiffness (MJS), and Severity of Worst Joint Pain are all single-item PROs designed to capture the severity of worst tiredness, MJS, and worst joint pain experienced that day, respectively. All three of these PROs are anchored at 0 and 10, where 0 represents "no tiredness," "no joint stiffness," or "no joint pain," and 10 represents "tiredness as bad as you can imagine," "joint stiffness as bad as you can imagine," or "joint pain as bad as you can imagine," respectively. The Duration of MJS is a single-item PRO designed to capture information on self-reported length of time, in minutes, that a patient's MJS lasted each day. Durations recorded as $>12 \mathrm{~h}(720 \mathrm{~min})$ were censored at $720 \mathrm{~min}$.

For RA-BEAM and RA-BUILD, all four PROs were assessed using a daily electronic diary through Week 12 . The Day 1 assessment was the first assessment at the end of the patient's day after the randomization visit (Week 0, Visit 2). The Week 1 assessment refers to the weekly average values from Days 2 to 8 . Assessments at Weeks $2,4,8$, and 12 refer to weekly average values of the 7 days prior to Weeks 2, 4, 8, and 12 visits, respectively. Recognizing that late shift workers (individuals who work outside of the hours of 9 am until $5 \mathrm{pm}$ ) could not complete the electronic diary (at home) at the end of Day 1, the Day 2 assessment (if available) was used to impute missing Day 1 values so that more patients could be included in the psychometric analyses utilizing the Day 1 value.

Medical Outcomes Study 36-Item Short Form Health Survey Version 2 Acute (SF-36) The SF-36 is a generic, 36-item PRO that measures general health status. The SF-36 includes eight domains of health status evaluated over the prior week: physical function, role limitationsphysical, bodily pain, general health perceptions, vitality, social function, role limitations-emotional, and mental health. Two component scores, the Physical Component Score (PCS) and the Mental Component Score (MCS), are derived based on the eight domain scores [24]. Domain and component scores are derived using established formulas [24], with higher scores indicating better health status or functioning.
Functional Assessment of Chronic Illness TherapyFatigue (FACIT-F) The FACIT-F scale [25] is a brief, 13-item, symptom-specific questionnaire that specifically assesses the self-reported severity of fatigue caused by chronic disease and its impact on daily activities and functioning. A 5-point Likert-type scale $(0=$ not at all; $1=$ a little bit; $2=$ somewhat; $3=$ quite a bit; $4=$ very much) is used. The range of possible scores is 0 to 52 , with 0 being the worst possible score (indicating greater fatigue) and 52 the best (indicating lesser fatigue).

Health Assessment Questionnaire-Disability Index (HAQ-DI) The HAQ-DI assesses patient physical function or disability. The HAQ-DI contains 24 questions that query the degree of difficulty a person has in accomplishing tasks in eight functional areas (dressing, arising, eating, walking, hygiene, reaching, gripping, and activities). Responses in each functional area are scored from 0 , indicating "no difficulty" in that area, to 3, indicating "inability to perform a task" in that area. The HAQ-DI total score, ranging from 0 to 3 (higher values indicate worse functioning), is obtained by summing the highest score within each functional area and dividing by the number of functional areas answered [26].

Quick Inventory of Depressive Symptomatology SelfRated-16 (QIDS-SR 16) The QIDS-SR $_{16}$ is a 16-item PRO intended to assess the existence and severity of symptoms of depression as listed in the American Psychiatric Association's Diagnostic and Statistical Manual of Mental Disorders, 4th Edition [27]. Patients were asked to consider each statement as it relates to the way they have felt for the past 7 days. There is a unique 4point ordinal scale for each item, with scores ranging from 0 to 3 reflecting increasing depressive symptoms as the item score increases. The instrument measures nine core symptom domains that are used to define a depressive episode: sad mood; concentration; self-criticism; suicidal ideation; interest; energy/fatigue; sleep disturbance; decrease or increase in appetite or weight; and psychomotor agitation or retardation. The QIDS-SR 16 total score is derived as the sum of the scores across the nine scale domains.

Patient's assessment of pain Patient's pain was assessed at each study visit with the use of a $0-100 \mathrm{~mm}$ visual analogue scale (VAS), with higher scores indicating more severe pain. Specifically, patients were asked, "How much pain are you currently having because of your rheumatoid arthritis?"

Patient's Global Assessment of Disease Activity (PtGA) The PtGA was assessed at each study visit and is 
recorded on a $0-100 \mathrm{~mm}$ VAS, with higher scores indicating more active RA.

\section{Clinician-reported assessments}

Physician's Global Assessment of Disease Activity (PhGA) The PhGA was assessed at each study visit and is recorded on a $0-100 \mathrm{~mm}$ VAS, with higher scores indicating more active RA.

\section{Clinical sign and symptom measures}

American College of Rheumatology 20 (ACR20) An ACR20 response (i.e., a binary variable indicating achieving or not achieving a response) was measured at each study visit and is defined as at least a $20 \%$ improvement from baseline in both tender joint count (TJC) (0 to 68) and swollen joint count (SJC) (0 to 66), and in at least three of the following five assessments: patient's assessment of pain, PtGA, PhGA, HAQ-DI, and hsCRP.

\section{Clinical Disease Activity Index (CDAI)}

The CDAI is a tool for measurement of disease activity in RA that integrates measures of physical examination, patient self-assessment, and evaluator assessment [28]. The CDAI was assessed at each study visit and is calculated by adding together scores from the following assessments: number of swollen joints (0 to 28), number of tender joints (0 to 28), PtGA on a VAS $(0$ to $10 \mathrm{~cm}$ ), and PhGA on a VAS (0 to $10 \mathrm{~cm}$ ). Total scores are calculated using established formulas [28]. Thresholds have been established for the CDAI (remission: $\leq 2.8$; low disease activity: $>2.8$ to $\leq 10$; moderate disease activity: $>10$ to $\leq 22$; high disease activity: $>22$ to $\leq 76$ ) [29].

\section{Disease activity score (28 joints) (DAS28)}

The DAS28 is a composite score that is based on a 28joint count (both TJC 0 to 28 and SJC 0 to 28), hsCRP or ESR, and PtGA and was measured at each study visit. Total scores are calculated using established formulas [30]. Patients can be categorized into four groups (remission: $<2.6$; low disease activity: $\geq 2.6$ to $\leq 3.2$; moderate disease activity: $>3.2$ to $\leq 5.1$; high disease activity: $>5.1$ ).

\section{Statistical analyses \\ Reliability (test-retest)}

For the assessment of test-retest reliability (which is used to assess if instrument scores are reproducible across time), stable patients were defined as patients with $\leq 5$ point difference [31] on the 0 to 100 PtGA between each assessment period, including between Weeks 1 and 2 and again between Weeks 4 and 8 . Intraclass correlation coefficients (ICCs) were calculated between Weeks 1 and 2 and again between Weeks 4 and 8 to evaluate test-retest reliability. An ICC of $\geq 0.70$ was considered good agreement [32].

Table 1 Patient Demographic and Disease Characteristics Patients with Electronic Diary Assessments at Day 1 and Patients with Week 12 Electronic Diary Assessments (mITT Population) for RA-BEAM and RA-BUILD

\begin{tabular}{|c|c|c|c|c|c|c|}
\hline \multirow[t]{2}{*}{ Characteristics } & \multicolumn{3}{|l|}{ RA-BEAM } & \multicolumn{3}{|l|}{ RA-BUILD } \\
\hline & $\begin{array}{l}\text { Total mlTT } \\
\text { Population } \\
\text { ( } n=1305)\end{array}$ & $\begin{array}{l}\text { Patients with } \\
\text { Day } 1 \text { Diary } \\
\text { Scores }(n=537)\end{array}$ & $\begin{array}{l}\text { Patients with } \\
\text { Week } 12 \text { Diary } \\
\text { Scores }^{\mathrm{a}}(n=1281)\end{array}$ & $\begin{array}{l}\text { Total mlTT } \\
\text { Population } \\
(n=684)\end{array}$ & $\begin{array}{l}\text { Patients with } \\
\text { Day } 1 \text { Diary } \\
\text { Scores }(n=312)\end{array}$ & $\begin{array}{l}\text { Patients with } \\
\text { Week } 12 \text { Diary } \\
\text { Scores }^{\mathrm{a}}(n=666)\end{array}$ \\
\hline \multicolumn{7}{|l|}{ Age (years) } \\
\hline Mean (SD) & $53.3(12.1)$ & $53.2(12.3)$ & $53.2(12.0)$ & $51.8(12.3)$ & $51.5(12.3)$ & $51.8(12.3)$ \\
\hline \multicolumn{7}{|l|}{ Gender, n (\%) } \\
\hline Female & $1009(77.3 \%)$ & $414(77.1 \%)$ & $989(77.2 \%)$ & $560(81.9 \%)$ & $262(84.0 \%)$ & $546(82.0 \%)$ \\
\hline \multicolumn{7}{|l|}{ Race, n (\%) } \\
\hline White & $818(62.7 \%)$ & $422(78.6 \%)$ & $801(62.5 \%)$ & $457(66.8 \%)$ & $254(81.4 \%)$ & $444(66.7 \%)$ \\
\hline Black or African American & $10(0.8 \%)$ & $5(0.9 \%)$ & $9(0.7 \%)$ & $28(4.1 \%)$ & $16(5.1 \%)$ & $27(4.1 \%)$ \\
\hline Asian & $392(30.0 \%)$ & $45(8.4 \%)$ & $388(30.3 \%)$ & $180(26.3 \%)$ & $31(9.9 \%)$ & $176(26.4 \%)$ \\
\hline American Indian or Alaska Native & $63(4.8 \%)$ & $49(9.1 \%)$ & $61(4.8 \%)$ & $14(2.0 \%)$ & $8(2.6 \%)$ & $14(2.1 \%)$ \\
\hline $\begin{array}{l}\text { Native Hawaiian or Other Pacific } \\
\text { Islander }\end{array}$ & $0(0.0 \%)$ & $0(0.0 \%)$ & $0(0.0 \%)$ & $1(0.1 \%)$ & $0(0.0 \%)$ & $1(0.1 \%)$ \\
\hline Multiple & $21(1.6 \%)$ & $16(3.0 \%)$ & $21(1.6 \%)$ & $3(0.4 \%)$ & $2(0.6 \%)$ & $3(0.5 \%)$ \\
\hline Missing & $1(0.1 \%)$ & $0(0.0 \%)$ & $1(0.1 \%)$ & $1(0.1 \%)$ & $1(0.3 \%)$ & $1(0.2 \%)$ \\
\hline \multicolumn{7}{|l|}{ Years from RA Diagnosis } \\
\hline Mean (SD) [Min, Max] & $8.7(8.2)[0-56]$ & $8.7(8.0)[0-40]$ & $8.6(8.1)[0-56]$ & $6.3(7.3)[0-53]$ & $6.2(6.5)[0-41]$ & $6.4(7.4)[0-53]$ \\
\hline
\end{tabular}

Abbreviations: Max = maximum; Min = minimum; $\mathrm{mlTT}=$ modified intent-to-treat; $\mathrm{n}=$ number of patients in the specified category; RA = rheumatoid arthritis; $\mathrm{SD}=$ standard deviation

${ }^{a}$ Daily average of seven days preceding visit that contained at least 4 measurements 


\section{Convergent and discriminant validity (construct validity)} Construct validity is the degree to which scores from one measure are related to those of other measures in a manner that is theoretically consistent. Pearson correlations at Day 1 and Week 12 were used to assess for the construct validity of Severity of Worst Tiredness. Correlations were calculated at Day 1 and Week 12 between Severity of Worst Tiredness and the scores of other clinical/PRO endpoints: Severity of MJS, Severity of Worst Joint Pain, Duration of MJS, SF-36 domain and component scores, FACIT-F, HAQ-DI, QIDS-SR ${ }_{16}$, patient's assessment of pain, PtGA, TJC28, SJC28, PhGA, and hsCRP. The strength of the correlations were interpreted using Cohen's conventions, where a correlation $>0.5$ is large, 0.3 to 0.5 is moderate, 0.1 to $<0.3$ is small, and $<0.1$ is insubstantial [33].
It was hypothesized that moderate or large correlations supporting convergent validity at Day 1 and Week 12 would be demonstrated between Severity of Worst Tiredness, and PRO instruments measuring concepts related to tiredness or fatigue (FACIT-F, SF-36 Vitality), other RA pain-like symptoms (Severity of MJS, SF-36 Bodily Pain, Severity of Worst Joint Pain, patient's assessment of pain), their impact on functioning (SF-36 Social Functioning, SF-36 Physical Functioning, HAQDI), and clinician-reported/laboratory assessments of disease activity (TJC28, SJC28, PhGA, and hsCRP). Discriminant validity was assessed by Pearson correlations at Day 1 and at Week 12 between Severity of Worst Tiredness, and PROs measuring distally related concepts (SF-36 MCS, SF-36 Role Emotional, QIDS-SR 16 ) where small correlations were hypothesized.

Table 2 Instrument Scores at Day 1 and Week 12 for RA-BEAM and RA-BUILD

\begin{tabular}{|c|c|c|c|c|}
\hline \multirow[t]{2}{*}{ Instrument } & \multicolumn{2}{|l|}{ RA-BEAM ${ }^{a}$} & \multicolumn{2}{|l|}{ RA-BUILD ${ }^{b}$} \\
\hline & Day 1 & Week 12 & Day 1 & Week 12 \\
\hline Severity of Worst Tiredness, Mean (SD) & $5.8(2.1)$ & $4.0(2.3)$ & $6.0(2.1)$ & $4.1(2.4)$ \\
\hline Duration of MJS, Mean (SD) & $152.8(180.8)$ & $96.7(144.7)$ & $160.7(174.8)$ & $103.5(147.5)$ \\
\hline Severity of MJS, Mean (SD) & $5.8(2.2)$ & $3.5(2.4)$ & $5.7(2.1)$ & $3.7(2.4)$ \\
\hline Severity of Worst Joint Pain, Mean (SD) & $6.1(2.0)$ & $4.0(2.3)$ & $6.0(2.1)$ & $4.2(2.4)$ \\
\hline Patient's Assessment of Pain, Mean (SD) & $60.8(22.3)$ & $34.9(24.1)$ & $58.0(22.1)$ & $36.5(24.9)$ \\
\hline PtGA, Mean (SD) & $62.4(21.8)$ & $36.3(23.5)$ & $60.7(21.1)$ & $37.7(24.0)$ \\
\hline \multicolumn{5}{|l|}{ SF-36 } \\
\hline Role Physical Domain, Mean (SD) & $35.5(10.4)$ & $41.8(10.2)$ & $35.3(9.2)$ & $40.7(9.6)$ \\
\hline Bodily Pain Domain, Mean (SD) & $34.7(7.8)$ & $42.5(8.7)$ & $34.9(7.6)$ & $41.9(9.0)$ \\
\hline General Health Domain, Mean (SD) & $36.8(8.5)$ & $41.6(8.9)$ & $36.8(8.3)$ & $42.0(9.4)$ \\
\hline Social Functioning Domain, Mean (SD) & $40.8(11.6)$ & $45.4(10.5)$ & $40.2(11.2)$ & $44.7(10.3)$ \\
\hline Vitality Domain, Mean (SD) & $43.7(10.0)$ & $49.4(9.8)$ & $41.9(10.1)$ & $48.4(10.0)$ \\
\hline Role Emotional Domain, Mean (SD) & $41.1(12.6)$ & $45.5(10.9)$ & $40.9(12.3)$ & $44.8(11.2)$ \\
\hline Mental Health Domain, Mean (SD) & $43.0(11.3)$ & $47.1(10.7)$ & $42.9(11.6)$ & $47.1(11.3)$ \\
\hline Physical Functioning Domain, Mean (SD) & $32.2(10.4)$ & $38.7(10.9)$ & $32.2(10.2)$ & $38.2(10.9)$ \\
\hline Mental Component Score, Mean (SD) & $46.4(11.8)$ & $49.8(10.8)$ & $45.7(11.8)$ & $49.3(11.1)$ \\
\hline Physical Component Score, Mean (SD) & $32.3(8.6)$ & $39.4(9.3)$ & $32.3(8.3)$ & $38.8(9.4)$ \\
\hline FACIT-F Total Score, Mean (SD) & $28.2(10.9)$ & $36.8(9.6)$ & $26.8(11.2)$ & $35.5(10.1)$ \\
\hline QIDS-SR $_{16}$ Total Score, Mean (SD) & $8.0(5.0)$ & $5.9(4.2)$ & $8.4(4.9)$ & $6.2(4.3)$ \\
\hline HAQ-DI Total Score, Mean (SD) & $1.56(0.68)$ & $1.03(0.70)$ & $1.52(0.61)$ & $1.03(0.66)$ \\
\hline PhGA, Mean (SD) & $65.0(16.9)$ & $31.0(21.7)$ & $63.5(17.4)$ & $33.9(22.4)$ \\
\hline CDAl, Mean (SD) & $37.83(12.55)$ & $18.68(13.54)$ & $36.05(12.12)$ & $18.04(13.15)$ \\
\hline DAS28-ESR, Mean (SD) & $6.43(0.97)$ & $4.62(1.46)$ & $6.22(0.97)$ & $4.50(1.37)$ \\
\hline DAS28-hsCRP, Mean (SD) & $5.73(0.94)$ & $3.93(1.39)$ & $5.55(0.91)$ & $3.84(1.35)$ \\
\hline
\end{tabular}

Abbreviations: CDAI = Clinical Disease Activity Index; DAS28 = Disease Activity Score modified to include the 28 diarthrodial joint count; ESR = erythrocyte sedimentation rate; FACIT-F = Functional Assessment of Chronic Illness Therapy-Fatigue; HAQ-DI = Health Assessment Questionnaire-Disability Index; hsCRP = highsensitivity C-reactive protein; $n=$ number of patients; MJS = morning joint stiffness; PhGA = Physician's Global Assessment of Disease Activity; PtGA = Patient's Global Assessment of Disease Activity; QIDS-SR ${ }_{16}=$ Quick Inventory of Depressive Symptomatology Self-Rated-16; SD = standard deviation; SF-36 = 36-Item Short Form Health Survey version 2 with Acute recall

${ }^{a}$ Daily diary responses were $n=537$ (Day 1) and $n=1281$ (Week 12); nondiary assessments had approximately $n=1301$ (Day 1 ) and $n=1250$ (Week 12)

${ }^{b}$ Daily diary responses were $n=310$ (Day 1) and $n=666$ (Week 12); nondiary assessments had approximately $n=680$ (Day 1 ) and $n=644$ (Week 12) 


\section{Known-groups validity}

Known-groups validity tests seek to demonstrate differences between two or more groups known to differ on the underlying construct [34]. An analysis of variance (ANOVA) model was used for the assessment of knowngroups validity at Day 1 and Week 4 to distinguish mean Severity of Worst Tiredness between subgroups defined by the DAS28-ESR thresholds $(<2.6 ; \geq 2.6$ and $\leq 3.2 ;>3.2$ and $\leq 5.1$; and $>5.1)$ and CDAI ( 0.0 to $\leq 2.8$; $>2.8$ to $\leq 10$; $>10$ to $\leq 22$; and $>22$ to $\leq 76$ ). The Scheffé adjustment was used for multiple comparisons. When subgroup

Table 3 Pearson Correlations between Severity of Worst Tiredness and Other Instruments in RA-BEAM and RA-BUILD at Day 1

\begin{tabular}{|c|c|c|c|c|}
\hline \multirow[t]{3}{*}{ Instruments } & \multicolumn{4}{|c|}{ Severity of Worst Tiredness } \\
\hline & \multicolumn{2}{|c|}{ RA-BEAM } & \multicolumn{2}{|c|}{ RA-BUILD } \\
\hline & $n$ & $r$ & $n$ & $r$ \\
\hline \multicolumn{5}{|l|}{ Day 1} \\
\hline Duration of MJS & 537 & $0.21^{* * *}$ & 311 & 0.09 \\
\hline Severity of MJS & 537 & $0.66^{* * *}$ & 311 & $0.52^{* * *}$ \\
\hline Severity of Worst Joint Pain & 537 & $0.70^{* * *}$ & 310 & $0.59^{* * *}$ \\
\hline \multicolumn{5}{|l|}{ SF-36 } \\
\hline Role Physical Domain & 535 & $-0.44^{* * *}$ & 311 & $-0.39^{* * *}$ \\
\hline Bodily Pain Domain & 535 & $-0.56^{* * *}$ & 311 & $-0.46^{* * *}$ \\
\hline General Health Domain & 535 & $-0.37^{* * *}$ & 311 & $-0.33^{* * *}$ \\
\hline Social Functioning Domain & 535 & $-0.44^{* * *}$ & 311 & $-0.35^{* * *}$ \\
\hline Vitality Domain & 535 & $-0.49^{* * *}$ & 311 & $-0.53^{* * *}$ \\
\hline Role Emotional Domain & 535 & $-0.35^{* * *}$ & 311 & $-0.21^{* * *}$ \\
\hline Mental Health Domain & 535 & $-0.39^{* * *}$ & 311 & $-0.31^{* * *}$ \\
\hline Physical Functioning Domain & 535 & $-0.47^{* * *}$ & 311 & $-0.38^{* * *}$ \\
\hline Mental Component Score & 535 & $-0.38^{* * *}$ & 311 & $-0.31^{* * *}$ \\
\hline Physical Component Score & 535 & $-0.47^{* * *}$ & 311 & $-0.41^{* * *}$ \\
\hline FACIT-F Total Score & 535 & $-0.57^{* * *}$ & 311 & $-0.60^{* * *}$ \\
\hline HAQ-DI Total Score & 535 & $0.48^{* * *}$ & 311 & $0.37^{* * *}$ \\
\hline QIDS-SR $_{16}$ Total Score & 535 & $0.40^{* * *}$ & 311 & $0.37^{* * *}$ \\
\hline Patient's Assessment of Pain & 535 & $0.43^{* * *}$ & 311 & $0.29^{* * *}$ \\
\hline PtGA & 535 & $0.45^{* * *}$ & 311 & $0.30^{* * *}$ \\
\hline Tender Joint Count 28 & 537 & $0.21^{* * *}$ & 311 & $0.30^{* * *}$ \\
\hline Swollen Joint Count 28 & 537 & $0.18^{* * *}$ & 311 & $0.20^{* * *}$ \\
\hline PhGA & 535 & $0.21^{* * *}$ & 304 & $0.20^{* * *}$ \\
\hline hsCRP & 535 & $0.37^{* * *}$ & 311 & $0.33^{* * *}$ \\
\hline
\end{tabular}

Abbreviations: FACIT-F = Functional Assessment of Chronic Illness TherapyFatigue; $\mathrm{HAQ}-\mathrm{DI}=\mathrm{Health}$ Assessment Questionnaire-Disability Index; hsCRP = high-sensitivity C-reactive protein; MJS = morning joint stiffness; $n=$ number of patients; PtGA = Patient's Global Assessment of Disease Activity; PhGA = Physician's Global Assessment of Disease Activity; QIDS-SR $_{16}=$ Quick Inventory of Depressive Symptomatology Self-Rated-16; SF-36 $=36$-Item Short Form Health Survey version 2 with Acute recall

Pearson correlation coefficients with significance using $p$-values denoted as: ${ }^{*} \leq 0.05,{ }^{* *} \leq 0.01,{ }^{* * *} \leq 0.001$ sample sizes were small (i.e., $<5 \%$ of the total sample size for the subgroup), subgroups were combined.

\section{Responsiveness}

Responsiveness, or the ability of the instrument to detect change over time [35], of Severity of Worst Tiredness was evaluated using an analysis of covariance (ANCOVA) methodology to assess significant differences in mean change in Severity of Worst Tiredness from Day 1 to Week 12 between ACR20 responders and nonresponders at Week 12, controlling for Day 1 Severity of Worst

Table 4 Pearson Correlations between Severity of Worst Tiredness and Other Instruments in RA-BEAM and RA-BUILD at Week 12

\begin{tabular}{|c|c|c|c|c|}
\hline \multirow[t]{3}{*}{ Instruments } & \multicolumn{4}{|c|}{ Severity of Worst Tiredness } \\
\hline & \multicolumn{2}{|c|}{ RA-BEAM } & \multicolumn{2}{|c|}{ RA-BUILD } \\
\hline & $n$ & $r$ & $n$ & $r$ \\
\hline \multicolumn{5}{|l|}{ Week $12^{a}$} \\
\hline Duration of MJS & 1281 & $0.32^{* * *}$ & 666 & $0.38^{* * *}$ \\
\hline Severity of MJS & 1281 & $0.79^{* * *}$ & 666 & $0.77^{* * *}$ \\
\hline Severity of Worst Joint Pain & 1281 & $0.82^{* * *}$ & 666 & $0.82^{* * *}$ \\
\hline \multicolumn{5}{|l|}{ SF-36 } \\
\hline Role Physical Domain & 1233 & $-0.45^{* * *}$ & 632 & $-0.42^{* * *}$ \\
\hline Bodily Pain Domain & 1233 & $-0.51^{* * *}$ & 632 & $-0.52^{* * *}$ \\
\hline General Health Domain & 1233 & $-0.39 * * *$ & 632 & $-0.38^{* * *}$ \\
\hline Social Functioning Domain & 1233 & $-0.43^{* * *}$ & 632 & $-0.44^{* * *}$ \\
\hline Vitality Domain & 1233 & $-0.52^{* * *}$ & 632 & $-0.51^{* * *}$ \\
\hline Role Emotional Domain & 1233 & $-0.41^{* * *}$ & 632 & $-0.32^{* * *}$ \\
\hline Mental Health Domain & 1233 & $-0.40^{* * *}$ & 632 & $-0.34^{* * *}$ \\
\hline Physical Functioning Domain & 1233 & $-0.43^{* * *}$ & 632 & $-0.41^{* * *}$ \\
\hline Mental Component Score & 1233 & $-0.40^{* * *}$ & 632 & $-0.34^{* * *}$ \\
\hline Physical Component Score & 1233 & $-0.45^{* * *}$ & 632 & $-0.45^{* * *}$ \\
\hline FACIT-F Total Score & 1233 & $-0.60^{* * *}$ & 632 & $-0.60^{* * *}$ \\
\hline HAQ-DI Total Score & 1233 & $0.49^{* * *}$ & 632 & $0.46^{* * *}$ \\
\hline QIDS-SR $_{16}$ Total Score & 1231 & $0.37^{* * *}$ & 632 & $0.37^{* * *}$ \\
\hline Patient's Assessment of Pain & 1233 & $0.69^{* * *}$ & 632 & $0.65^{* * *}$ \\
\hline PtGA & 1233 & $0.64^{* * *}$ & 632 & $0.62^{* * *}$ \\
\hline Tender Joint Count 28 & 1231 & $0.32^{* * *}$ & 630 & $0.40^{* * *}$ \\
\hline Swollen Joint Count 28 & 1231 & $0.21^{* * *}$ & 630 & $0.23^{* * *}$ \\
\hline PhGA & 1224 & $0.35^{* * *}$ & 627 & $0.38^{* * *}$ \\
\hline hsCRP & 1220 & $0.46^{* * *}$ & 623 & $0.49^{* * *}$ \\
\hline
\end{tabular}

Abbreviations: FACIT-F = Functional Assessment of Chronic Illness TherapyFatigue; HAQ-DI = Health Assessment Questionnaire-Disability Index; hsCRP = high-sensitivity C-reactive protein; MJS = morning joint stiffness; $n=$ number of patients; PtGA = Patient's Global Assessment of Disease Activity; PhGA =

Physician's Global Assessment of Disease Activity; QIDS-SR ${ }_{16}=$ Quick Inventory of Depressive Symptomatology Self-Rated-16; SF-36 = 36-Item Short Form Health Survey version 2 with Acute recall

Pearson correlation coefficients with significance using $p$-values denoted as: ${ }^{*} \leq 0.05,{ }^{* *} \leq 0.01,{ }^{* * *} \leq 0.001$

${ }^{a}$ Daily average of seven days preceding visit that contained at least

4 measurements 
Tiredness. A parallel analysis was also conducted to assess responsiveness using disease activity as measured by DAS28-hsCRP at Week 12, using the following subgroups: DAS28-hsCRP $<2.6$, DAS28-hsCRP $\geq 2.6$ and DAS28hsCRP $\leq 3.2$, and DAS28-hsCRP $>3.2$. An overall statistically significant difference $(p<0.05)$ with statistically significant subgroup comparisons was hypothesized.

\section{Handling of missing data}

Only patients with Day 1 data were included in analyses at Day 1. For analyses of data at Week 12, scores collected in the 7 days prior to the Week 12 visit date were used. If there were fewer than 4 nonmissing assessments, the 7day window was shifted back in time (toward baseline) one day at a time until there were 4 nonmissing assessments available in the 7-day window. Then, the average of the 4 assessments was used in the Week 12 analysis.

\section{Results}

Baseline demographics for the total modified intent-totreat population, patients with Day 1 diary scores, and patients with Week 12 diary scores are provided in Table 1. Scores for all other patient- and cliniciancompleted assessments, as well as clinical sign and symptom measures, are found in Table 2.

A large amount of missing data was present at the Day 1 assessment period (Tables 1 and 2). These missing data were due to multiple reasons as shown in Additional file 1: Table S1, such as the diary device alarm not sounding until the following day or the diary device being given to the patient after Day 1. Sensitivity analyses with the imputation for missing data at Day $1(n=1041$ for RA-BEAM and $n=563$ for RA-BUILD, respectively) were conducted and demonstrated similar findings to the results presented here.

\section{Reliability (test-retest)}

From Weeks 1 to 2, ICCs for weekly mean severity of worst tiredness ranged from 0.90 to 0.91 (RA-BEAM $n=412$; RA-BUILD $n=185$ ) and from 0.89 to 0.91 from Week 4 to Week 8 (RA-BEAM $n=417$; RA-BUILD $n=$ 215). These values provide evidence for substantial testretest reliability among stable patients.

\section{Convergent and discriminant validity}

Results supporting convergent validity of Severity of Worst Tiredness in terms of its relationship with other clinical outcome assessments are presented in Table 3 at Day 1 and Table 4 at Week 12. At Day 1 in RA-BEAM and RA-BUILD, moderate-to-large associations between Severity of Worst Tiredness and other assessments measuring similar tiredness-like patient states were demonstrated. These associations were found to be large at Week 12 in RA-BEAM and RA-BUILD, including the
Table 5 Known-Groups Validity of Severity of Worst Tiredness Using DAS28-ESR Subgroups at Day 1 and Week 4

\begin{tabular}{llll}
\hline PRO/Study & \multicolumn{2}{l}{ DAS28-ESR Category } & p-value \\
\cline { 2 - 3 } & $\leq 5.1$ & $>5.1$ \\
N, Mean (SD) & N, Mean (SD) \\
\hline
\end{tabular}

Severity of Worst

Tiredness Day 1

\begin{tabular}{llll} 
RA-BEAM & $39,4.7(2.6)$ & $496,5.9(2.1)$ & $0.001^{\mathrm{a}}$ \\
RA-BUILD & $36,5.0,(1.9)$ & $273,6.2(2.0)$ & $0.002^{\mathrm{a}}$ \\
$\begin{array}{l}\text { Severity of Worst } \\
\text { Tiredness Week 4 }\end{array}$ & & & \\
RA-BEAM & $619,3.6(2.1)$ & $587,5.3(1.9)$ & $0.001^{\mathrm{a}}$ \\
RA-BUILD & $327,3.7(2.0)$ & $286,5.5(2.0)$ & $0.001^{\text {a }}$ \\
\hline
\end{tabular}

Abbreviations: DAS28 = Disease Activity Score modified to include the 28 diarthrodial joint count; $\mathrm{ESR}=$ erythrocyte sedimentation rate;

$\mathrm{SD}=$ standard deviation;

${ }^{a} p$-value based on a comparison of mean values using ANOVA

FACIT-F ( $r=-0.60$ in both studies) and SF-36 Vitality $(r=-0.52$ and -0.51$)$. In addition, Severity of Worst Tiredness also demonstrated moderate-to-large associations with measures of other RA symptoms of pain and stiffness at Day 1. These associations increased at Week 12 in RA-BEAM and RA-BUILD, respectively, including SF-36 Bodily Pain $(r=-0.51$ and -0.52$)$, Worst Joint Pain ( $r=0.82$ and 0.83$)$, Severity of MJS ( $r=0.79$ and $0.77)$, and patient's assessment of pain $(r=0.69$ and 0.65 ). The Severity of Worst Tiredness also demonstrated moderate-to-large associations with concepts related to patient physical and social functioning at Day 1 that increased at Week 12, in RA-BEAM and RABUILD, respectively, including SF-36 Social Functioning $(r=-0.43$ and -0.44$)$, SF-36 Physical Functioning $(r=$ -0.43 and -0.41$)$, and HAQ-DI $(r=0.49$ and 0.46$)$. These findings provide support for the convergent validity of Severity of Worst Tiredness in patients with moderately to severely active RA.

Small-to-moderate correlations were observed between Severity of Worst Tiredness and SF-36 MCS $(r=$ -0.38 and -0.31$)$ and SF-36 Role Emotional $(r=-0.35$ and -0.21$)$ at Day 1 , as well as QIDS-SR $_{16}(r=0.40$ to 0.37 ) in RA-BEAM and RA-BUILD, respectively,

Table 6 Known-Groups Validity of Severity of Worst Tiredness Using CDAI Subgroups at Day 1

\begin{tabular}{llll}
\hline PRO/Study & CDAl Category & & $p$-value \\
\cline { 2 - 3 } & 0.0 to $\leq 22.0$ & $>22.0$ to $\leq 76.0$ & \\
N, Mean (SD) & N, Mean (SD) & \\
\hline
\end{tabular}

Severity of Worst

Tiredness Day 1

\begin{tabular}{llll} 
RA-BEAM & $36,4.9(2.6)$ & $497,5.9(2.1)$ & $0.007^{\mathrm{a}}$ \\
RA-BUILD & $26,4.8(2.1)$ & $278,6.1(2.0)$ & $0.016^{\mathrm{a}}$ \\
\hline
\end{tabular}

Abbreviations: $\mathrm{SD}=$ standard deviation; $\mathrm{CDAI}=$ Clinical Disease Activity Index ${ }^{a} p$-value based on a comparison of mean values using ANOVA 
Table 7 Known-Groups Validity of Severity of Worst Tiredness Using CDAI Subgroups at Week 4

\begin{tabular}{|c|c|c|c|c|c|}
\hline \multirow[t]{2}{*}{ PRO/Study } & \multicolumn{3}{|l|}{ CDAl Category } & \multirow[t]{2}{*}{$p$-value } & \multirow[t]{2}{*}{ Comparisons $^{\mathrm{b}}$} \\
\hline & $\begin{array}{l}0.0 \text { to } \leq 10.0 \\
N, \text { Mean (SD) }\end{array}$ & $\begin{array}{l}>10.0 \text { to } \leq 22.0 \\
\text { N, Mean (SD) }\end{array}$ & $\begin{array}{l}>22.0 \text { to } \leq 76.0 \\
\text { N, Mean (SD) }\end{array}$ & & \\
\hline \multicolumn{6}{|c|}{ Severity of Worst Tiredness Week 4} \\
\hline RA-BEAM & $220,2.9(2.0)$ & $426,4.2(2.1)$ & $567,5.1(2.0)$ & 0.001 & a: 0.001, b: $0.001, c: 0.001$ \\
\hline RA-BUILD & $134,3.1(2.0)$ & 209, $4.1(1.9)$ & $275,5.6(2.0)$ & 0.001 & a: $0.001, b: 0.001, c: 0.001$ \\
\hline
\end{tabular}

Abbreviations: $\mathrm{SD}=$ standard deviation; $\mathrm{CDAl}=$ Clinical Disease Activity Index

${ }^{a} p$-value based on a comparison of mean values using ANOVA

${ }^{\mathrm{b}}$ Note for multiple comparison using Scheffé adjustment: $\mathrm{a}$ : 0.0 to $\leq 10.0$ versus $>10.0$ to $\leq 22.0$; $\mathrm{b}$ : 0.0 to $\leq 10.0$ versus $>22.0$ to $\leq 76.0$; c: $>10.0$ to $\leq 22.0$

versus $>22.0$ to $\leq 76.0$

indicating that these assessments measure more distally related constructs as hypothesized.

\section{Known-groups validity}

Because small sample sizes in the lower DAS28-ESR subgroups at Day 1 (i.e., $<5 \%$ of the sample in each score category), patients were categorized into two subgroups: $\leq 5.1$ and $>5.1$ (Table 5). At Day 1 in RA-BEAM and RABUILD, patients with higher DAS28-ESR scores reported a significantly greater Severity of Worst Tiredness score than those patients with lower DAS28-ESR scores (Table 5). Similar results were found for both studies at Week 4 .

Similarly, because of small sample sizes, patients were categorized into two subgroups based on the CDAI at Day $1(0.0$ to $\leq 22.0$ and $>22.0$ to $\leq 76.0)$ and three subgroups at Week 4 ( 0.0 to $\leq 10.0,>10.0$ to $\leq 22.0$, and $>22.0$ to $\leq 76.0$ ). At Day 1 , patients in the higher CDAI score subgroup experienced a significantly greater Severity of Worst Tiredness in both RA-BEAM and RABUILD than those patients in the lower CDAI score subgroup (Table 6). Similar results were found for both studies at Week 4 (Table 7). These findings provide evidence that Severity of Worst Tiredness is able to distinguish between known groups based on disease severity.

\section{Responsiveness}

The responsiveness of Severity of Worst Tiredness was supported through large and statistically significant differences in mean change from Day 1 to Week 12 in
Severity of Worst Tiredness between ACR20 responders and non-responders (Table 8). Similar findings supporting responsiveness of Severity of Worst Tiredness were seen when using DAS28-hsCRP as an anchor. Pairwise comparisons assessing for significant differences in mean change between DAS28-hsCRP subgroups of $<2.6$ versus $\geq 3.2$ ( $p=0.001$ for both studies), and $\geq 2.6$ and $<3.2$ versus $\geq 3.2$ ( $p=0.001$ for both studies) were statistically significant (Table 8). However, the comparisons between change scores for subgroups $<2.6$ versus $\geq 2.6$ and $<3.2$ were not statistically significant for either study.

\section{Discussion}

An investigation into the psychometric properties of Severity of Worst Tiredness PRO using data from patients with moderately to severely active RA provided support for the reliability, validity, and responsiveness of this measure. Analyses of test-retest reliability indicated strong agreement in Severity of Worst Tiredness scores across two assessment periods in stable patients. The construct (convergent and divergent) validity of Severity of Worst Tiredness was also supported, as a priori hypotheses of the associations between Severity of Worst Tiredness and related PROs, clinician-reported measures, and laboratory assessments were supported at Day 1 and Week 12. Using the DAS28-ESR and CDAI as indicators of known clinical status, known-groups validity was supported as mean Severity of Worst Tiredness values were significantly different between predefined groups. Lastly, Severity of Worst

Table 8 Change in Severity of Worst Tiredness from Day 1 to Week 12 among ACR20 and DAS28-hsCRP Groups

\begin{tabular}{|c|c|c|c|c|c|c|c|}
\hline \multirow{2}{*}{$\begin{array}{l}\text { PRO/Study/ } \\
\text { Statistics }\end{array}$} & \multicolumn{2}{|c|}{ ACR20 Category at Week 12} & \multirow[t]{2}{*}{$p$-value } & \multicolumn{3}{|c|}{ DAS28-hsCRP Groups at Week $12^{b}$} & \multirow[t]{2}{*}{ Comparisons $^{c}$} \\
\hline & Responder $^{a}$ & Nonresponder $^{a}$ & & DAS28-hsCRP $<2.6$ & $2.6 \leq$ DAS28-hsCRP $<3.2$ & DAS28-hsCRP $\geq 3.2$ & \\
\hline $\begin{array}{l}\text { RA-BEAM; N, } \\
\text { Mean (SD) }\end{array}$ & $326,-2.5(2.5)$ & $211,-1.0(2.1)$ & 0.001 & $88,-3.1(2.7)$ & $79,-2.4(2.4)$ & $368,-1.5(2.3)$ & a: $0.069 ;$ b: $0.001 ;$ c: 0.001 \\
\hline $\begin{array}{l}\text { RA-BUILD; N, } \\
\text { Mean (SD) }\end{array}$ & $174,-2.6(2.6)$ & $137,-0.9(2.0)$ & 0.001 & $61,-2.9(2.8)$ & $33,-2.6(3.2)$ & $214,-1.5(2.2)$ & a: $0.846 ;$ b: $0.001 ; c: 0.001$ \\
\hline
\end{tabular}

Abbreviations: ACR20 $=20 \%$ improvement in American College of Rheumatology criteria; DAS28 = Disease Activity Score modified to include the 28 diarthrodial joint count; hsCRP = high-sensitivity C-reactive protein; $\mathrm{SD}=$ standard deviation

${ }^{a}$ Responder: Achievement of ACR20 criteria at Week 12; Nonresponder: Failure to achieve ACR20 criteria at Week 12

${ }^{\mathrm{b}}$ Missing DAS28-hsCRP at Week 12 was imputed using modified baseline observation carried forward

'Note for multiple comparison: a: $<2.6$ vs. $\geq 2.6$ and $<3.2 ;$ b: $<2.6$ vs. $\geq 3.2 ;$ c: $\geq 2.6$ and $<3.2$ vs. $\geq 3.2$

${ }^{\mathrm{d}}$ Daily average of seven days preceding visit that contained at least 4 measurements 
Tiredness demonstrated responsiveness to change from Day 1 to Week 12 when defining responders using the ACR20 or DAS28-hsCRP as an anchor.

Patients have identified tiredness/fatigue as a bothersome and debilitating disease-related symptom $[8,9]$, and despite improved treatment options for other RA symptoms, improvement in fatigue continues to be noted as an unmet need for patients with RA [18]. This was recently demonstrated in an analysis of data from the Leiden Early Arthritis Clinic cohort of patients with RA [36]. Cohort inclusion occurred when RA was confirmed at physical examination and symptom duration was $<2$ years (early RA). Early RA treatment strategies evolved over time, such that initial treatment for patients enrolled from 1993 to 1995 was nonsteroidal anti-inflammatory drugs (NSAIDs) (DMARDs were used later in treatment); patients enrolled from 1996 to 1998 were treated with nonMTX DMARDs (usually hydroxychloroquine or sulfasalazine); or patients enrolled from 1999 to 2007 were treated with MTX. A longitudinal study of 626 patients from these three cohorts demonstrated that despite improved treatment strategies over time associated with less severe radiographic progression in $\mathrm{RA}$, there was no effect on fatigue severity over many years of treatment in early RA patients $(p=0.96)$ [36]. The authors concluded that a reliable and valid PRO measure of this symptom is an important tool to aid clinicians in treating patients with RA, thereby facilitating doctor-patient communication to improve the quality of patient care, contribute to better patient outcomes, and help to address this need [37]. Thus, the Severity of Worst Tiredness PRO addresses this unmet need. Given the increasing use of electronic PRO diaries in clinical settings, this instrument could be utilized in a clinical practice where patients are asked to report their worst tiredness symptom daily, thus enhancing the dialogue between patients and care providers. The reliability and ability to detect change over time has been demonstrated and further supports the use of this instrument as a simple, single-item instrument of RA-related tiredness.

Although Severity of Worst Tiredness did display strong evidence of reliability, validity, and responsiveness, a key limitation to this study is the missing data at the Day 1 assessment. These missing data were due to multiple reasons such as the missed alarms. However, sensitivity analyses after imputing missing Day 1 Severity of Worst Tiredness scores were conducted and all study conclusions remained the same. The timespan of the baseline assessment is also a limitation in that it only consisted of one study day's data versus the average of up to the 7 days of assessments, as used in the Week 12 endpoint.

\section{Conclusion}

The results from the present study demonstrate that the single-item, daily measure, Severity of Worst Tiredness, is suitable to validly and reliably measure a key symptom of RA that is important to patients with moderately to severely active RA.

\section{Additional file}

Additional file 1: Table S1. Reasons for Missing Diary Data at Day 1 for RA-BEAM and RA-BUILD. (DOC $29 \mathrm{~kb}$ )

\begin{abstract}
Abbreviations
ACR: American College of Rheumatology; ACR20: 20\% improvement in American College of Rheumatology criteria; ANCOVA: analysis of covariance; ANOVA: analysis of variance; CSDMARD: conventional synthetic DMARD; DAS28: Disease Activity Score modified to include the 28 diarthrodial joint count; DMARD: disease-modifying antirheumatic drug; ESR: erythrocyte sedimentation rate; EULAR: European League Against Rheumatism; FACITF: Functional Assessment of Chronic Illness Therapy-Fatigue; HAQ-DI: Health Assessment Questionnaire-Disability Index; HRQOL: health-related quality of life; hSCRP: high-sensitivity C-reactive protein; ICC: intraclass correlation coefficient; MCS: Mental Component Score; MJS: Morning Joint Stiffness; NSAID: nonsteroidal anti-inflammatory drug; OMERACT: Outcome Measures in Rheumatology Clinical Trials; PCS: Physical Component Score;

PhGA: Physician's Global Assessment of Disease Activity; PRO: patientreported outcome; PtGA: Patient's Global Assessment of Disease Activity; QIDS-SR 16 : Quick Inventory of Depressive Symptomatology Self-Rated-16; RA: rheumatoid arthritis; SJC: swollen joint count; TJC: tender joint count; TNF: tumor necrosis factor; VAS: visual analogue scale
\end{abstract}

\section{Acknowledgements}

Not applicable.

Funding

This study was funded by Eli Lilly and Company and Incyte Corporation.

\section{Availability of data and materials}

Lilly provides access to the individual patient data from studies on approved medicines and indications as defined by the sponsor specific information on ClinicalStudyDataRequest.com.

This access is provided in a timely fashion after the primary publication is accepted. Researchers need to have an approved research proposal submitted through clinicalstudydatarequest.com. Access to the data will be provided in a secure data sharing environment after signing a data sharing agreement.

\section{Authors' contributions}

All authors contributed substantially to the design of the study, the interpretation of the results, and the editing of the manuscript. All authors read and approved the final manuscript.

Ethics approval and consent to participate

The study was approved by the Copernicus Group IRB in Research Triangle Park, NC (IRB Tracking \#: PAR1-09-143). Ethics approval was also obtained for all 41 sites. All patients provided written informed consent.

\section{Consent for publication}

Not applicable.

\section{Competing interests}

EDB and KWW were employees of Evidera at the time of this investigation, and received financial support from Eli Lilly in connection with the development of the manuscript. AMD, CYL, CLG, XZ, TR, SdB and RH are all full-time employees of Eli Lilly and Company. TR is a minor share holder of Eli Lilly and Company.

\section{Publisher's Note}

Springer Nature remains neutral with regard to jurisdictional claims in published maps and institutional affiliations. 


\section{Author details}

${ }^{1}$ Evidera, Inc., 1417 4th Avenue, Suite 510, Seattle, WA 98101, USA. ${ }^{2}$ Eli Lilly and Company, Indianapolis, IN, USA. ${ }^{3}$ Evidera Inc., Bethesda, MD, USA.

Received: 21 April 2017 Accepted: 22 November 2017

Published online: 06 December 2017

\section{References}

1. Boers M, Tugwell P, Felson DT, van Riel PL, Kirwan JR, Edmonds JP, Smolen JS, Khaltaev N, Muirden KD. World Health Organization and international league of associations for rheumatology core endpoints for symptom modifying antirheumatic drugs in rheumatoid arthritis clinical trials. J Rheumatol Suppl. 1994:41:86-9.

2. Felson DT, Anderson JJ, Boers M, Bombardier C, Chernoff M, Fried B, Furst D, Goldsmith C, Kieszak S, Lightfoot R, et al. The American College of Rheumatology preliminary core set of disease activity measures for rheumatoid arthritis clinical trials. The committee on outcome measures in rheumatoid arthritis clinical trials. Arthritis Rheum. 1993;36:729-40.

3. Tugwell $P$, Boers M. Developing consensus on preliminary core efficacy endpoints for rheumatoid arthritis clinical trials. OMERACT committee. J Rheumatol. 1993;20:555-6.

4. Carr A, Hewlett S, Hughes R, Mitchell H, Ryan S, Carr M, Kirwan J. Rheumatology outcomes: the patient's perspective. J Rheumatol. 2003;30: 880-3.

5. Sierakowski S, Cutolo M. Morning symptoms in rheumatoid arthritis: a defining characteristic and marker of active disease. Scand J Rheumatol Suppl. 2011;125:1-5.

6. Kristiansen TM, Primdahl J, Antoft R, Horslev-Petersen K. Everyday life with rheumatoid arthritis and implications for patient education and clinical practice: a focus group study. Musculoskeletal Care. 2012;10:29-38.

7. Wolfe F, Hawley DJ, Wilson K. The prevalence and meaning of fatigue in rheumatic disease. J Rheumatol. 1996;23:1407-17.

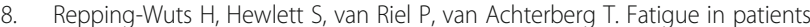
with rheumatoid arthritis: British and Dutch nurses' knowledge, attitudes and management. J Adv Nurs. 2009;65:901-11.

9. Hewlett S, Cockshott Z, Byron M, Kitchen K, Tipler S, Pope D, Hehir M. Patients' perceptions of fatigue in rheumatoid arthritis: overwhelming, uncontrollable, ignored. Arthritis Rheum. 2005;53:697-702.

10. Belza BL. Comparison of self-reported fatigue in rheumatoid arthritis and controls. J Rheumatol. 1995;22:639-43.

11. Hewlett S, Hehir M, Kirwan JR. Measuring fatigue in rheumatoid arthritis: a systematic review of scales in use. Arthritis Rheum. 2007;57:429-39.

12. Suurmeijer TP, Waltz M, Moum T, Guillemin F, van Sonderen FL, Briancon S, Sanderman R, van den Heuvel WJ. Quality of life profiles in the first years of rheumatoid arthritis: results from the EURIDISS Iongitudinal study. Arthritis Rheum. 2001:45:111-21.

13. Rupp I, Boshuizen HC, Jacobi CE, Dinant HJ, van den Bos GA. Impact of fatigue on health-related quality of life in rheumatoid arthritis. Arthritis Rheum. 2004;51:578-85.

14. Kirwan JR, Minnock P, Adebajo A, Bresnihan B, Choy E, de Wit M, Hazes M, Richards P, Saag K, Suarez-Almazor M, et al. Patient perspective: fatigue as a recommended patient centered outcome measure in rheumatoid arthritis. J Rheumatol. 2007:34:1174-7.

15. Aletaha D, Landewe R, Karonitsch T, Bathon J, Boers M, Bombardier C, Bombardieri S, Choi $\mathrm{H}$, Combe B, Dougados $\mathrm{M}$, et al. Reporting disease activity in clinical trials of patients with rheumatoid arthritis: EULAR/ACR collaborative recommendations. Arthritis Rheum. 2008:59:1371-7.

16. Hewlett S, Chalder T, Choy E, Cramp F, Davis B, Dures E, Nicholls C, Kirwan J. Fatigue in rheumatoid arthritis: time for a conceptual model. Rheumatology (Oxford). 2011;50:1004-6

17. Nicassio PM, Ormseth SR, Custodio MK, Irwin MR, Olmstead R, Weisman MH A multidimensional model of fatigue in patients with rheumatoid arthritis. J Rheumatol. 2012;39:1807-13.

18. Druce $\mathrm{KL}$, Jones GT, Macfarlane GJ, Basu N. Patients receiving anti-TNF therapies experience clinically important improvements in RA-related fatigue: results from the British Society for Rheumatology biologics register for rheumatoid arthritis. Rheumatology (Oxford). 2015;54:964-71.

19. Fatigue and arthritis. https://www.arthritisresearchuk.org/arthritisinformation/daily-life/fatigue.aspx

20. Krupp LB. Fatigue in multiple sclerosis: a guide to diagnosis and management. New York: Demos Medical Publishing, Inc.; 2004.
21. DeLozier AM, Gaich CL, Vernon MK, von Maltzahn R. Content validity evaluation of a new diary developed to evaluate symptoms important to patients with moderate-to-severe rheumatoid arthritis. In: ISPOR 20th Annual International Meeting; May 16-20. Philadelphia; 2015.

22. Taylor PC, Keystone EC, van der Heijde D, Weinblatt ME, Del Carmen ML, Reyes Gonzaga J, Yakushin S, Ishii T, Emoto K, Beattie S, et al. Baricitinib versus placebo or adalimumab in rheumatoid arthritis. N Engl J Med. 2017; 376:652-62.

23. Dougados $M$, van der Heijde $D$, Chen $Y C$, Greenwald M, Drescher E, Liu J, Beattie S, Witt S, de la Torre I, Gaich C, et al. Baricitinib in patients with inadequate response or intolerance to conventional synthetic DMARDs: results from the RA-BUILD study. Ann Rheum Dis. 2017;76:88-95.

24. Ware JE Jr, Sherbourne CD. The MOS 36-item short-form health survey (SF36). I. Conceptual framework and item selection. Med Care. 1992;30:473-83.

25. Cella D, Webster K. Linking outcomes management to quality-of-life measurement. Oncology (Williston Park). 1997;11:232-5.

26. Fries JF, Spitz PW, Young DY. The dimensions of health outcomes: the health assessment questionnaire, disability and pain scales. J Rheumatol. 1982;9:789-93.

27. American Psychiatric Association. Diagnostic and statistical manual of mental disorders (DSM-IV). 4th ed. Washington, DC: American Psychiatric Association; 1994

28. Aletaha D, Smolen J. The simplified disease activity index (SDAI) and the clinical disease activity index (CDAl): a review of their usefulness and validity in rheumatoid arthritis. Clin Exp Rheumatol. 2005;23:S100-8.

29. Felson DT, Smolen JS, Wells G, Zhang B, van Tuyl LH, Funovits J, Aletaha D, Allaart CF, Bathon J, Bombardieri S, et al. American College of Rheumatology/European league against rheumatism provisional definition of remission in rheumatoid arthritis for clinical trials. Ann Rheum Dis. 2011; 70:404-13.

30. Fransen J, Stucki G, van Riel PLCM. Rheumatoid arthritis measures: disease activity score (DAS), disease activity Score-28 (DAS28), rapid assessment of disease activity in rheumatology (RADAR), and rheumatoid arthritis disease activity index (RADAI). Arthritis and Rheumatism (Arthritis Care \& Research). 2003:49:S214-24.

31. DeLoach LJ, Higgins MS, Caplan AB, Stiff JL. The visual analog scale in the immediate postoperative period: intrasubject variability and correlation with a numeric scale. Anesth Analg. 1998:86:102-6.

32. Nunnally JC, Bernstein IH. Psychometric theory. 3rd ed. New York: McGrawHill; 1994

33. Cohen J. Statistical power analysis for the behavioral sciences. 2nd ed. Hillsdale: Lawrence Erlbaum Associates; 1988.

34. Stewart AL, Hays RD, Ware JE. Methods of validating MOS health measures. Durham: Duke University Press; 1992.

35. Hays RD, Revicki D. Reliability and validity (including responsiveness). In: Fayers P, Hays RD, editors. Assessing Quality of Life in Clinical Trials: Methods and Practice. 2nd edition. New York: Oxford University Press; 2005: 25-39. [Fayers P (Series Editor): Assessing Quality of Life in Clinical Trials].

36. van Steenbergen HW, Tsonaka R, Huizinga TW, Boonen A, van der Helm-van Mil AH. Fatigue in rheumatoid arthritis; a persistent problem: a large longitudinal study. RMD Open. 2015;1:e000041.

37. Sokka T. Morning stiffness and other patient-reported outcomes of rheumatoid arthritis in clinical practice. Scand J Rheumatol Suppl. 2011;125:23-7.

\section{Submit your next manuscript to BioMed Central and we will help you at every step:}

- We accept pre-submission inquiries

- Our selector tool helps you to find the most relevant journal

- We provide round the clock customer support

- Convenient online submission

- Thorough peer review

- Inclusion in PubMed and all major indexing services

- Maximum visibility for your research

Submit your manuscript at www.biomedcentral.com/submit 